\title{
Endovascular repair of aortic arch lesions in high-risk patients or after previous aortic surgery: Midterm results
}

\author{
Ludovic Canaud, MD, Kheira Hireche, MD, Jean-Philippe Berthet, MD, Pascal Branchereau, MD, \\ Charles Marty-Ané, MD, PhD, and Pierre Alric, MD, PhD
}

\begin{abstract}
Objective: The aim of this study was to assess the short- and midterm results after endovascular repair of the aortic arch in high-risk patients or after previous aortic surgery.
\end{abstract}

\begin{abstract}
Methods: From November 1998 to November 2008, 57 thoracic stent grafts were implanted in 44 patients (sex ratio, 4.5 ; mean age, $66.5 \pm 16.5$ years) for aortic arch repair (zone 0 to 2 according to the arch map proposed by Ishimaru) of 19 degenerative aneurysms, 12 traumatic transections of the aorta, 8 complicated aortic dissections, 4 postcoarctectomy aortic pseudoaneurysms, and 1 penetrating atheromatous ulcer. All patients were considered to be at high surgical risk owing to serious comorbidities (American Society of Anesthesiologists score $\geq$ III [79.5\%]) or previous aortic surgery. Endovascular repair was performed in an emergency setting in $27.3 \%$ $(n=12)$ of the patients. Thirty-four underwent a hybrid technique with supra-aortic debranching and simultaneous or staged endovascular stent grafting. Debranching was performed to provide an adequate proximal aortic landing zone, in 28 patients by a cervical approach and in 6 patients by a sternotomy approach.
\end{abstract}

Results: The technical success rates for aortic zone 0 patients $(n=6)$, zone 1 patients $(n=4)$, and zone 2 patients $(\mathrm{n}=34)$ were, respectively, $100 \%, 100 \%$, and $97 \%$. The 30 -day mortality rate was $20.4 \%$. The actuarial survival was $70 \%$ over a mean follow-up of 29.9 months. The rate of stroke was $6.8 \%$. Two $(4.5 \%)$ cases of paraplegia were observed, 1 of which was reversible after cerebrospinal fluid drainage. The rate of endoleak was $15.9 \%(\mathrm{n}=7): 3$ type I, 3 type II, and 1 type III. There were no cases of device migration, but 1 stent-graft collapse occurred 20 days after exclusion of an aortic traumatic transection.

Conclusion: Hybrid endovascular aortic arch reconstructions, although some of these adjunctive procedures remain major operations, provide attractive alternatives for treating aortic arch lesions in high-risk patients who would otherwise be unsuitable for open repair, with acceptable primary results and encouraging midterm efficacy to prevent rupture. (J Thorac Cardiovasc Surg 2010;140:52-8)

Conventional surgical repair of aortic arch diseases requires arch replacement during deep hypothermic circulatory arrest for cerebral protection. Mortality and morbidity associated with transverse aortic arch replacement in the standard risk population has decreased over the past decades as various modifications of surgical technique have been introduced. Despite these recent advances, reconstruction of the aortic arch remains a challenge, particularly in elderly patients, in patients requiring emergency repair, or in those with major pre-existing comorbidities. Furthermore, many of these patients are deemed unsuitable for open repair.

Aortic arch diseases or extension of all descending thoracic aortic pathologic conditions toward the major aortic side are often deemed unsuitable for endovascular repair

From the Department of Vascular and Thoracic Surgery Arnaud de Villeneuve Hospital, Montpellier, France.

Disclosures: None.

Received for publication March 13, 2009; revisions received July 30, 2009; accepted for publication Sept 8, 2009; available ahead of print Nov 18, 2009.

Address for reprints: Pierre Alric, MD, PhD, Service de Chirurgie Vasculaire et

Thoracique, Hôpital Arnaud de Villeneuve, 191 avenue du Doyen Gaston

Giraud-34090-Montpellier, France (E-mail: p-alric@chu-montpellier.fr).

$0022-5223 / \$ 36.00$

Copyright (c) 2010 by The American Association for Thoracic Surgery

doi:10.1016/j.jtcvs.2009.09.022 owing to the close proximity of the supra-aortic trunks. A combined endovascular and open approach has therefore recently been adopted as a valuable alternative, ${ }^{1}$ consisting in supra-aortic debranching and revascularization followed by stent-graft deployment. Debranching is performed to provide an appropriate landing zone for the stent graft and to preserve perfusion to the supra-aortic trunks.

Endovascular repair presents a particular challenge owing to the involvement of supra-aortic trunks, the anatomic curvature of the arch, the high blood flow in the area, and substantial movement of this portion of the aorta at each heartbeat.

The aim of this study was to assess short- and midterm results of hybrid endovascular aortic arch repair in patients deemed unsuitable for open surgery (American Society of Anesthesiologists [ASA] score $\geq 3$ ) or in patients with previous aortic arch repair.

\section{METHOD \\ Patients \\ From November 1998 to August 2008, 44 patients required stent-graft landing in the aortic arch: zone 0 to 2 (aortic arch map proposed by Ishi- $\operatorname{maru}^{1}$ ). Among them, 34 underwent a hybrid technique with supra-aortic debranching and simultaneous or staged endovascular stent grafting to treat}




\section{Abbreviations and Acronyms \\ ASA = American Society of Anesthesiologists \\ $\mathrm{BT}=$ brachiocephalic trunk \\ LCCA $=$ left common carotid artery \\ LSA = left subclavian artery}

complex aortic arch disease. There were 36 men and 8 women (mean age, $66.5 \pm 16.5$ years; range, $19-89$ years).

All patients were unfit for open surgery because of serious comorbidities (ASA $\geq$ III, $\mathrm{n}=35,79.5 \%)$ or a history of thoracic aortic open repair $(\mathrm{n}=$ $11,25 \%)$. Furthermore, $12(27.3 \%)$ operations were performed in an emergency setting.

Nineteen $(43.2 \%)$ patients had a degenerative aneurysm, 4 of which had ruptured. Eight (18.2\%) patients had a complicated aortic dissection (6 dissecting aneurysms, 1 rupture of acute type $B$ dissection, and 1 proximal type I endoleak, which arose 7 years after endovascular repair of a painful type B dissection). Twelve (27.3\%) patients had a traumatic transection of the aortic isthmus; 5 of them were in hemodynamically unstable condition. Four $(9 \%)$ patients had postcoarctectomy aortic pseudoaneurysm and $1(2.3 \%)$ patient had a ruptured penetrating atherosclerotic ulcer. Further preoperative data are shown in Table 1.

All 44 patients were considered to have an inadequate proximal landing zone for aortic arch stent-graft insertion, but only 34 (77.3\%) of them underwent surgical supra-aortic debranching and revascularization-via a cervical approach in 28 patients and through a median sternotomy in 6 patients. Regarding the 10 remaining patients, the coverage of the left subclavian artery (LSA) without prior revascularization was required to allow a swift procedure owing to the hemodynamically unstable state. Patients were divided into 3 groups according to the proximal landing zone: 0 , 1 , or 2 (Figure 1). Zone 0 was involved in 6 patients, zone 1 in 4 patients, and zone 2 in 34 patients.

\section{Surgical Approach}

All procedures took place in the operating room with the patient under general anesthesia. Debranching procedures were performed before the deployment of the stent grafts. Endovascular repair was performed in the same operating setting in $24(54.5 \%)$ patients.

Debranching and revascularization of supra-aortic trunks with a prosthetic graft was performed in all zone 0 cases through a median sternotomy; after systemic heparinization and partial crossclamping of the ascending aorta, proximal end-to-side anastomosis was performed with a prosthetic 10-mm graft, followed by 2 end-to-side anastomoses to the brachiocephalic trunk (BT) and the left common carotid artery (LCCA) and an end-to-end anastomosis to the LSA.

In zone 1 patients, extra-anatomic revascularization of the LCCA and LSA was performed with an LCCA transposition in the BT or with a carotidcarotid bypass, followed by a left carotid-subclavian transposition.

Regarding zone 2 patients, revascularization of the LSA was performed with a left carotid-subclavian transposition in hemodynamically stable patients, whereas in unstable patients, the LSA was deliberately covered.

\section{Stent Graft}

Four different stent grafts were used: the Excluder TAG device (W. L. Gore \& Associates, Inc, Flagstaff, Ariz) in 32 patients, the Talent device (Medtronic Vascular, Santa Rosa, Calif) in 2 patients, the Valiant device (Medtronic Vascular) in 9 patients, and the Zenith TX device (Cook Inc, Bloomington, Ind) in 1 patient.
The mean number of stent graft used was $1.3 \pm 0.6$ (range 1-3) and the mean stent-graft diameter was $35.6 \pm 5.4 \mathrm{~mm}$ (range $24-40 \mathrm{~mm}$ ).

\section{Endovascular Repair}

All patients underwent contrast-enhanced computed tomographic scan to assess the feasibility of endoluminal repair, sizing of stent grafts, and implant strategy. Thirty-one (70.4\%) patients had an additional preoperative aortic arch angiography. Suitable morphology for stent-graft placement requires a proximal aortic neck length of at least $15 \mathrm{~mm}$. Measurements from preprocedural imaging data were used to select the appropriate diameter and length of the stent graft. Devices were oversized by $10 \%$ to $20 \%$ greater than the minor axis of the aortic neck to provide sufficient radial force for adequate fixation. All patients underwent preoperative computed tomographic scan of the femoral, iliac, and supra-aortic arteries to evaluate access vessels and supra-aortic trunks.

Prophylactic use of cerebrospinal fluid drainage to prevent spinal cord ischemia was not used. The endovascular devices were delivered via the common femoral artery. A 260-cm, 0.035-inch guidewire (Terumo Medical Corporation, Tokyo, Japan) was placed, via the common femoral artery, under fluoroscopic control (digital C-arm) into the ascending aorta; a 5F calibrated pigtail catheter was advanced into the ascending aorta over the guidewire. This pigtail catheter was used to exchange the guidewire for an extra-stiff guidewire (Lunderquist; Cook Inc); angiography was performed through a $4 \mathrm{~F}$ pigtail catheter advanced into the right subclavian artery through the right brachial artery. The stent graft was deployed under fluoroscopic control. A baseline angiogram was performed before and after stent-graft deployment to confirm proper position of the stent graft and complete exclusion of the lesion. Ballooning was performed selectively.

\section{Follow-up and Statistical Analysis}

Follow-up surveillance was performed with serial computed tomographic scans at 1 week, then at 3,6, and 12 months, and annually thereafter. Outcomes were analyzed by Kaplan-Meier life table analysis.

\section{RESULTS (TABLES 2-5) Overall}

Forty-four patients were treated for lesions involving zone 0 to 2 of the aortic arch. The mean proximal aortic diameter was $29.8 \pm 4.7 \mathrm{~mm}$. The mean distal aortic diameter was $24.8 \pm 4.5 \mathrm{~mm}$. The mean proximal aortic neck length was $19.5 \pm 4.7 \mathrm{~mm}$. The mean distal aortic neck length was $20 \mathrm{~mm}$ in 2 patients and more than $30 \mathrm{~mm}$ in the remaining patients. The mean length of the covered aorta was 180 $\pm 92.3 \mathrm{~mm}$. The mean diameter of the aneurysms was $64.5 \mathrm{~mm} \pm 12.6$ (range, 50-102 $\mathrm{mm}$ ).

Technical success was obtained in $97.7 \%$ of the patients. A patient treated for a ruptured aneurysm had an intraoperative proximal type I endoleak left untreated. The 30-day mortality rate (Table 2) was $20.4 \%$ (9/44). The actuarial survival was $70 \%$ over a mean follow-up of $29.9 \pm 30.1$ months (Figure 2). The rate of cerebrovascular accident was $6.8 \%$ : 1 fatal stroke, 1 transient ischemic accident, and 1 intracranial hematoma from which the patient completely recovered. Two $(4.5 \%)$ cases of paraplegia were observed, 1 of which was reversible after cerebrospinal fluid drainage. The rate of endoleak was $15.9 \%(\mathrm{n}=7): 3$ $(6.8 \%)$ type I, $3(6.8 \%)$ type II, and $1(2.2 \%)$ type III. There were no instances of device migration, but 1 stent-graft 
TABLE 1. Preoperative patient demographics data

\begin{tabular}{|c|c|c|}
\hline & $\mathbf{N}$ & $\%$ \\
\hline Age (mean, y) & $66.5 \pm 16.5$ & \\
\hline Gender $(\mathrm{M} / \mathrm{F})$ & $36 / 8$ & $81.8 / 18.2$ \\
\hline \multicolumn{3}{|l|}{ Pathology } \\
\hline Degenerative aneurysm & 19 & 43.2 \\
\hline Ruptured aneurysm & 4 & 9 \\
\hline Symptomatic aneurysm & 6 & 13.6 \\
\hline Asymptomatic aneurysm & 9 & 20.5 \\
\hline Complicated type B dissection & 8 & 18.2 \\
\hline Acute rupture & 1 & 2.3 \\
\hline Dissecting aneurysm & 6 & 13.6 \\
\hline Type I endoleak after previous TEVAR & 1 & 2.3 \\
\hline Traumatic aortic transection & 12 & 27.3 \\
\hline Postcoarctectomy aortic pseudoaneurysm & 4 & 9 \\
\hline Penetrating ulcer & 1 & 2.3 \\
\hline \multicolumn{3}{|l|}{ Preoperative comorbidities } \\
\hline Chronic cardiac failure & 3 & 6.8 \\
\hline Coronary artery disease & 10 & 22.7 \\
\hline Chronic renal failure & 5 & 11.3 \\
\hline Chronic obstructive pulmonary disease & 8 & 18.2 \\
\hline Hypertension & 22 & 50 \\
\hline Diabetes mellitus & 3 & 6.8 \\
\hline Previous cerebrovascular accident & 3 & 6.8 \\
\hline ASA score $\geq$ III & 35 & 79.5 \\
\hline ASA III & 13 & 29.5 \\
\hline ASA IV & 13 & 29.5 \\
\hline ASA V & 9 & 20.4 \\
\hline History of aortic surgery & 21 & 47.7 \\
\hline Descending thoracic aorta & 7 & 15.9 \\
\hline Ascending thoracic aorta & 4 & 9 \\
\hline Abdominal aorta & 10 & 22.7 \\
\hline Emergency repair & 12 & 27.2 \\
\hline Ruptured & 10 & 22.7 \\
\hline Painful aneurysm & 2 & 4.5 \\
\hline
\end{tabular}

TEVAR, Thoracic endovascular aortic repair; ASA, American Society of Anesthesiologists.

collapse occurred 20 days after exclusion of an aortic traumatic transection.

\section{According to the Zone}

Zone 0. Debranching and revascularization of the supraaortic trunk with a prosthetic graft was performed in 6 cases through a median sternotomy followed by endovascular stent grafting. Technical success was obtained in all. In a case of acute aortic arch angulation, establishment of a brachiofemoral wire, which is held on each end to straighten the angulated aortic arch. Stabilizing the route and advancement of the delivery sheath, allowed the deployment of the stent graft in zone 0 . Early postoperative complications requiring secondary surgical intervention were sternal disunion and cardiac tamponade in 1 case each. The 30-day mortality rate was $0 \%$. One case of transient paraplegia and one transient ischemic accident were observed. One type II endoleak was observed that resolved spontaneously. One case of retrograde type A dissection occurred on the fourth postoperative day after aortic clamping; the patient underwent immediate surgical conversion with ascending aortic replacement under circulatory arrest and suture between the prosthetic graft and the stent graft, which resulted in a favorable outcome. There were no instances of device migration.

Zone 1. Four patients underwent LCCA revascularization and carotid-subclavian transposition followed by endovascular stent grafting. Technical success was obtained in all the patients. One iliac artery rupture occurred peroperatively and was treated by implantation of a covered stent: Wallgraft (Boston Scientific, Natick, Mass). One patient died on the 15th postoperative day related to a massive myocardial infarction. No instances of cerebrovascular accident, paraplegia, or endoleak were observed. There was no device migration.

Zone 2. Twenty-four patients underwent a carotid-subclavian transposition, and in the 10 remaining patients, the ostium of the LSA was deliberately covered because the patients were in hemodynamically unstable condition (3 ruptured aneurysms, 5 transections of the aortic isthmus, 1 ruptured type $\mathrm{B}$ dissection, and 1 penetrating atheromatous ulcer). Technical success was obtained in $97 \%$ of the 34 patients. An 86-year old man, treated for a ruptured aneurysm, died with a proximal type I endoleak left untreated. This endoleak was related to an incomplete proximal sealing owing to a lack of adequate oversizing: at this time, the largest available commercial thoracic device had a diameter of 40 $\mathrm{mm}$, and the proximal neck was $39 \mathrm{~mm}$ in diameter.

Accidental coverage of the BT occurred in 1 patient. The inflow was rapidly recovered by transcarotid insertion of a self-expanding stent with a high radial force alongside the thoracic endograft. After 1 year of follow-up, the stent placed in the LCCA completely collapsed, leading to a 70\% stenosis of the LCCA and BT. Therefore, an ascending aorta to BT and LCCA bypass was performed through a median sternotomy. Accidental coverage of the LCCA occurred in 3 patients. In 1 case, the stent graft was pulled distally by traction by low-pressure inflated balloon. Regarding the remaining patients, the inflow was recovered by stenting of the left common artery. One iliac artery rupture occurred peroperatively and was treated by implantation of a covered stent: Wallgraft (Boston Scientific). One postoperative cervical hematoma required secondary surgical intervention.

One $(2.9 \%)$ case of paraplegia was observed. The rate of cerebrovascular accident was 5.8\%: 1 fatal stroke and 1 intracranial hematoma from which the patient completely recovered. The 30 -day mortality rate was $23.5 \%$. The causes of death were heart failure in 3 patients, multiple organ failure in 1 patient, stroke in 1 patient, postoperative acute rupture of the aorta in a patient treated for a ruptured acute aortic type B dissection, hepatic failure in a cirrhotic patient, and finally failure of exclusion (type I endoleak) in 1 patient. 


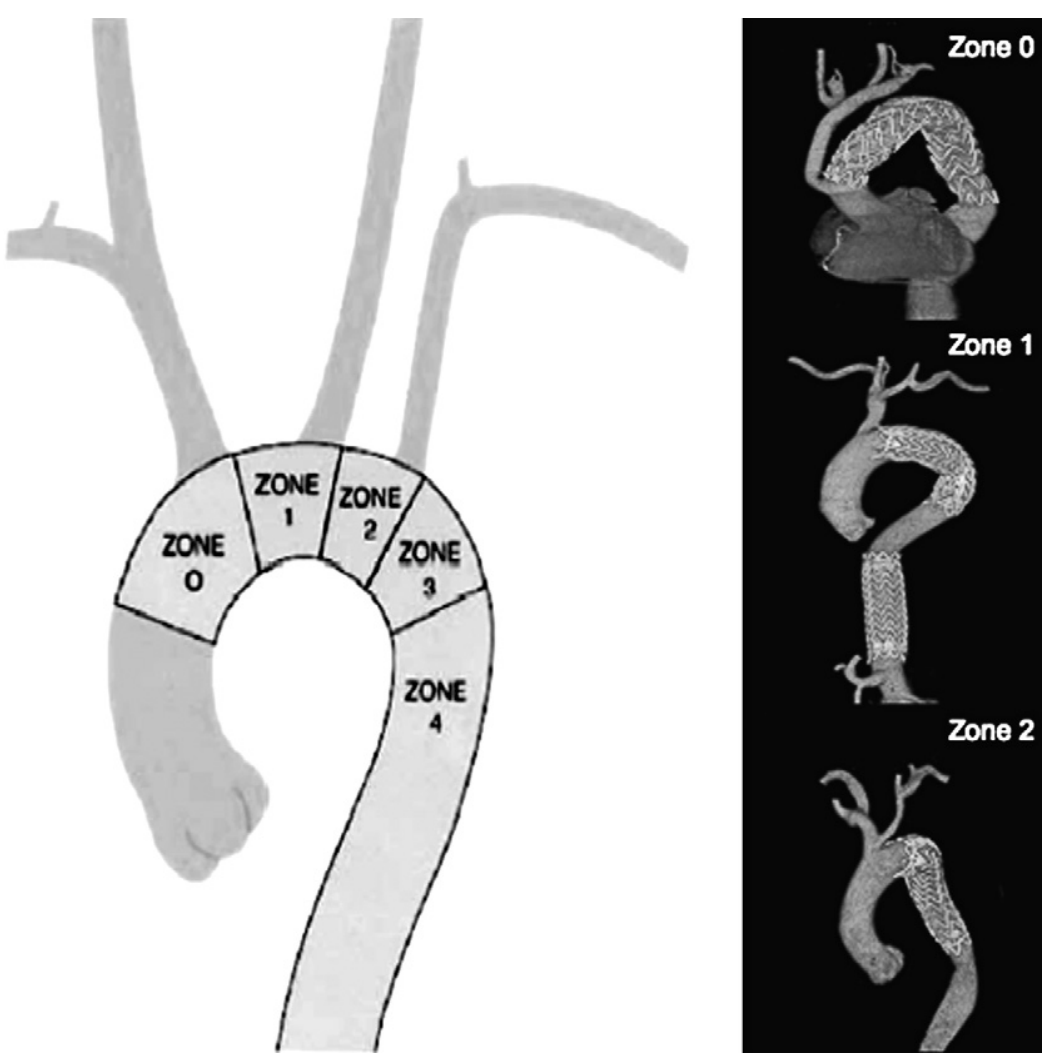

FIGURE 1. Ishimaru arch map and illustrations of the different debranching procedures according to the different landing zones

The rate of endoleak was $17.6 \%(n=6): 3$ type I endoleaks, 2 type II endoleaks, and 1 type III endoleak. In 2 patients, a type I endoleak was treated by proximal implantation of a second stent graft after the fulfillment of carotid-carotid bypass to provide an adequate proximal landing zone. Regarding type II endoleaks, 1 patient underwent LSA embo- lization that allowed complete exclusion of a ruptured aneurysm; the second endoleak spontaneously resolved. A type III endoleak was successfully managed by deployment of a second stent graft. There was no device migration, but a stent-graft collapse occurred 20 days after exclusion of a traumatic transection of the aorta. The stent graft was

TABLE 2. Causes of early death (in 30 postoperative days)

\begin{tabular}{|c|c|c|c|c|c|c|}
\hline & Age (y) & Sex & $\begin{array}{c}\text { Elective or } \\
\text { emergency repair }\end{array}$ & Aortic arch disease & Comorbidities & $\begin{array}{l}\text { Complications/ } \\
\text { cause of death }\end{array}$ \\
\hline 1 & 75 & M & Elective & Degenerative aneurysm & $\begin{array}{l}\text { Cardiac, respiratory and } \\
\text { renal failure, hypertension }\end{array}$ & Stroke, ARDS \\
\hline 2 & 71 & M & Elective & Degenerative aneurysm & $\begin{array}{l}\text { Respiratory failure, hypertension, } \\
\text { coronary artery disease }\end{array}$ & Massif myocardial infarction \\
\hline 3 & 79 & $\mathrm{~F}$ & Elective & Dissecting aneurysm & $\begin{array}{l}\text { Renal failure, diabetes, } \\
\text { hypertension }\end{array}$ & $\begin{array}{l}\text { Cardiac failure } \\
\text { (hypertensive pulmonary } \\
\text { oedema) }\end{array}$ \\
\hline 4 & 80 & M & Emergency & Ruptured degenerative aneurysm & Coronary artery disease & $\begin{array}{l}\text { Type I endoleak } \\
\text { (failure of exclusion) }\end{array}$ \\
\hline 5 & 52 & M & Elective & $\begin{array}{l}\text { Type I endoleak after acute type } \\
\text { B dissection endovascular repair }\end{array}$ & $\begin{array}{l}\text { Cirrhosis hepatisis, } \\
\text { hypertension }\end{array}$ & Hepatic failure \\
\hline 6 & 80 & M & Emergency & Rupture of acute type B dissection & Hypertension & Aortic rupture \\
\hline 7 & 77 & $\mathrm{~F}$ & Emergency & Rupture of a penetrating ulcer & Hypertension & Multiple organ failure \\
\hline 8 & 70 & M & Emergency & Ruptured aneurysm & Ascending aneurysm repair & Cardiac failure \\
\hline 9 & 64 & M & Elective & Degenerative aneurysm & Renal failure, diabetes & Cardiac failure, paraplegia \\
\hline
\end{tabular}


TABLE 3. Thirty-day mortality according to the proximal landing zone

\begin{tabular}{lccc}
\hline & Global & Elective cases & $\begin{array}{c}\text { Emergency } \\
\text { cases }\end{array}$ \\
\hline $\mathrm{n}$ & 44 & 32 & 12 \\
Mortality & $9(20.4 \%)$ & $5(15.6 \%)$ & $4(30 \%)$ \\
Zone 0 & 6 & $5(83.3 \%)$ & $1(16.7 \%)$ \\
Mortality & $0(0 \%)$ & $0(0 \%)$ & $0(0 \%)$ \\
Zone 1 & 4 & $3(75 \%)$ & $1(25 \%)$ \\
Mortality & $1(25 \%)$ & $1(33.3 \%)$ & $0(0 \%)$ \\
Zone 2 & 34 & $23(67.6 \%)$ & $11(32.4 \%)$ \\
Mortality & $8(23.5 \%)$ & $4(17.4 \%)$ & $4(36.4 \%)$ \\
\hline
\end{tabular}

successfully re-expanded by deployment of a second stent graft. For 2 of the 10 patients in whom the ostium of the LSA was deliberately covered, an LSA-LCCA transposition was secondarily performed to treat vertebrobasilar insufficiency.

\section{DISCUSSION}

Repair of the aortic arch is a surgical dilemma, mainly owing to the adverse neurologic sequelae ranging from $1 \%$ to $10 \% .^{2}$ The surgical outcome has been improving lately. However, a recent report ${ }^{3}$ indicated that the 30 -day mortality after aortic arch surgery in the standard risk population (renal failure $5 \%$, diabetes melitlitus $7 \%$, prior cerebrovascular accident $9 \%$, prior myocardial infarction $7 \%$ ) ranges from $4 \%$ to $28.6 \%$ according to the adjunctive measures for cerebral protection used (profound hypothermia and antegrade or retrograde cerebral perfusion) and to mode of presentation (elective or emergency). Furthermore, many patients are deemed unsuitable owing to serious comorbidities. As a consequence, a less invasive approach would be even more favorable to patients.

Since the first report by Dake and associates, ${ }^{4}$ endovascular management has emerged during the past decade as a valuable treatment modality for descending thoracic aortic diseases and was recently proposed for delicate anatomic regions such as the aortic arch. Stent grafting the aortic arch brings new challenges: stent grafts are subject to greater dynamic aortic motion than in the abdominal segment related to its curved configuration. Furthermore, physicians have to deal with the branches of the aortic arch to provide an adequate proximal landing. Recent reports ${ }^{5-7}$ have demonstrated the technical feasibility of complete or partial debranching of the supra-aortic trunks associated with endovascular repair of the aortic arch.

TABLE 4. Thirty-day mortality in patients with a history of thoracic aortic surgery

\begin{tabular}{lccc}
\hline & Global & Elective cases & Emergency cases \\
\hline $\mathrm{n}$ & 11 & 8 & 3 \\
Thirty-day mortality & $2(18.1 \%)$ & $0(0 \%)$ & $2(66.6 \%)$ \\
\hline
\end{tabular}

TABLE 5. Thirty-day mortality in patients without a history of thoracic aortic surgery

\begin{tabular}{lccc}
\hline & Global & Elective cases & Emergency cases \\
\hline $\mathrm{n}$ & 33 & 24 & 9 \\
Thirty-day mortality & $7(21 \%)$ & $6(25 \%)$ & $1(11.1 \%)$ \\
ASA score & & III: 11 & \\
& & IV: 13 & \\
\hline
\end{tabular}

ASA, American Society of Anesthesiologists.

In patients with a short proximal aortic neck, the LSA can be overstented to effectively exclude thoracic aortic lesions. In case of overstenting of the LSA, an LSA-LCCA transposition should be preferred inasmuch as efficacy and longterm patency are better as compared with the outcome of bypasses. ${ }^{8}$ In an emergency setting, coverage of the LSA can be performed without prior revascularization if mandatory for adequate anchoring. LSA revascularization can be proposed in a second operative time either in case of left arm ischemia or in case of vertebrobasilar insufficiency. In elective cases, eventual coverage of the LSA should be discussed before endovascular repair. A meta-analysis of Peterson and coworkers ${ }^{9}$ showed that morbidity relative to LSA revascularization before stent-graft repair was lower than morbidity in cases of LSA coverage without revascularization $(3 \%$ vs $23 \%)$. Furthermore, Buth and associates ${ }^{10}$ assessed the significance of clinical factors that potentially influenced the occurrence of neurologic sequelae during endovascular repair of the thoracic aorta: perioperative paraplegia or paraparesis was significantly associated with blockage of the LSA without revascularization. Maintaining normal perfusion of the ipsilateral vertebral artery allows the prevention of ischemia of the brainstem and, furthermore, preserving major collaterals of the vertebral artery that contribute to spinal blood flow protects against spinal cord ischemia when multiple intercostal vessels are covered during thoracic endovascular repair. Revascularization of a dominant left vertebral artery and/or associated lesions of other supra-aortic arteries justifies LSA revascularization to reduce the rate of postoperative cerebral vascular accidents. ${ }^{11}$

Patients who have thoracic aneurysms with a short neck distal to the LCCA are best treated with total coverage of the LCCA. The potential sources of inflow in these cases include the right common carotid, subclavian, axillary, or femoral vessels. The simplest reconstructions for this purpose are LCCA transposition in the BT or carotid-carotid bypass, which is performed through a cervical approach.

Patients with arch aneurysms that involve the portion of the arch adjacent to the BT require total aortic arch debranching to obtain an adequate proximal landing zone. Total arch transposition by a sternotomy approach, with partial crossclamping of the ascending aorta, leads to a longer proximal landing zone. This is tolerated by even fairly sick patients from a cardiovascular standpoint. The quality of the 


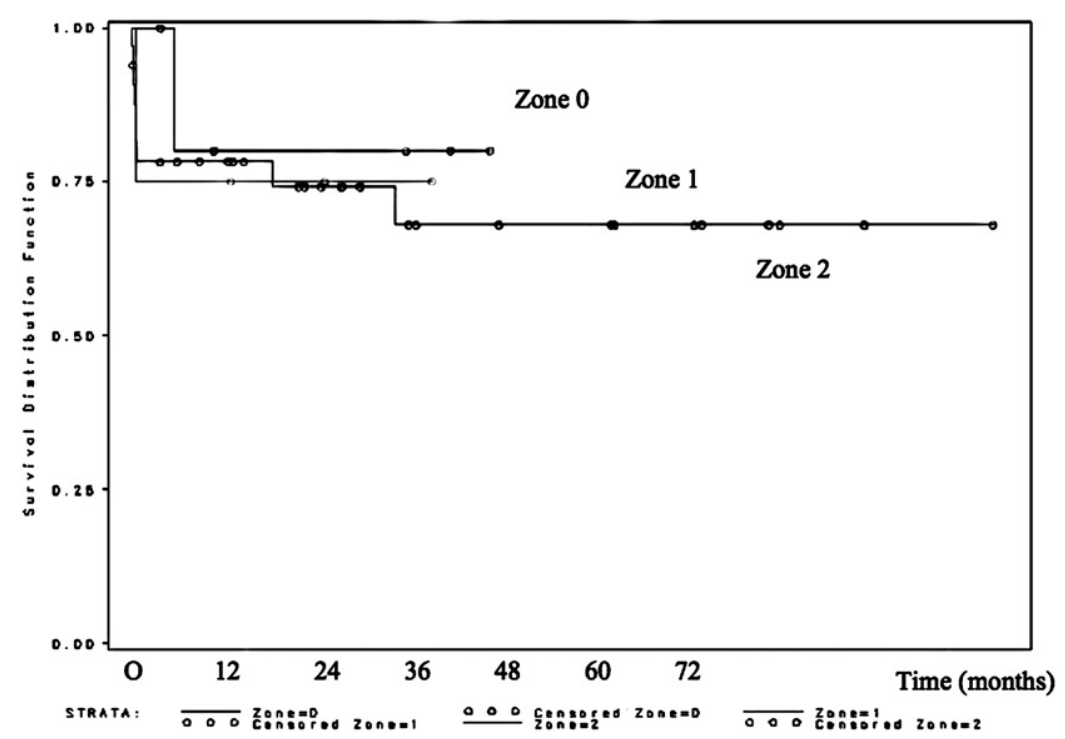

FIGURE 2. Kaplan-Meier life table analysis of survival according to the proximal landing zone.

ascending aorta is an important factor to consider. The aorta must not be severely calcified or aneurysmal.

Our preference is to perform simultaneous debranching procedures. The advantage is that in case of a failure of exclusion, an open surgical treatment option can be proposed: external banding of the proximal landing zone or an additional debranching procedure. Furthermore, rupture of the aneurysm may occur after the debranching procedure, while the patients are waiting for staged endovascular treatment. Most of the staged procedures were performed at the beginning of our experiences. However, simultaneous procedures often require much longer operating times and are more stressful for the patient and the surgeon. Additionally, renal function may be more affected by simultaneous procedures because of surgical blood loss and contrast load.

Overall results of our retrospective study indicate a high rate of clinical success $(97.7 \%)$, a low rate of permanent paraplegia $(2.2 \%)$ or paraparesis $(2.2 \%)$, and a low rate of stroke $(6.8 \%)$. Considering the preoperative clinical status of our patients, $79.5 \%$ of our patients were in critical condition at the time of surgery (ASA $>$ III) or had an history of thoracic aortic open repair $(n=11,25 \%)$. Furthermore, $27.3 \%$ were treated in an emergency setting, which might explain the high mortality rate observed $(20.4 \%)$.

Retrograde dissection is an issue. The reported incidence of retrograde dissection after thoracic stent-graft repair seems to be about $1 \%$ to $2 \% .^{12,13}$ This complication arises from wire manipulation in the aortic arch during the endovascular procedure, from the lack of conformability of most currently available thoracic stent grafts to the aortic curve in an angulated aortic arch that may injure the aortic wall, from excessive oversizing, especially in case of acute type B dissection, ${ }^{13}$ and from aortic wall stress related to balloon dilations. The design of the stent graft also has been involved (presence or absence of a proximal bare stent segment); the rate of retrograde dissection appears similar for both the TAG and the Talent thoracic stent grafts. ${ }^{12}$

Atheroembolic complications remain challenging during aortic arch repair, even in case of endovascular repair. Careful manipulation of central vessels as well as keeping crossclamp times short to avoid exceeding the ischemic frame of cerebral tissue is mandatory for success. Furthermore, the wires in the aortic arch have to be manipulated cautiously to avoid soft plaque detachment.

Other endovascular approaches have also been reported. Chuter and associates ${ }^{14}$ reported the use of a modular branched stent graft for endovascular repair of aortic arch. The disadvantages of this modular approach are the potential for subsequent disassembly, the required time to manufacture and deliver such custom-made stent grafts for urgent cases, and the high cost of this kind of modular devices. Criado ${ }^{15}$ reported a percutaneous endovascular technique by retrograde puncture of the LCCA to deal with stent-graft coverage of the origin of the supra-aortic trunks during thoracic endovascular aortic repair: "interposition" of a bare metal stent between a thoracic stent graft and the aortic wall allows preservation of arch branch patency during thoracic endovascular aortic repair and stenting by focally displacing the stent-graft device. This alternative does not appear adequate with regard to the uncertain durability of this option and should only be considered in case of preoperative inadvertent coverage of the supra-aortic trunks. Inoue and colleagues ${ }^{16}$ have demonstrated the feasibility of using unibody stent grafts to repair the aortic arch. However, a high rate of embolism was associated with this technique and is probably related to the complexities of multibranched unibody stent-graft deployment. 
Current thoracic stent grafts do not meet the needs. Thoracic stent grafts are designed for the descending thoracic aorta, which is straight, and thus most of them are unable to conform to the inner curve of the aortic arch. ${ }^{17}$ Furthermore, discrepancy in the diameter of the proximal landing zone (ascending aorta) and distal landing zone (descending thoracic aorta) is often observed. Improvements of the stent-graft design are required with more flexible and tapered designs or with multibranched modular stent grafts.

Kouchoukos and associates ${ }^{18}$ reported results of the "clam-shell" repair of chronic dissection; 46 of 51 patients had prior operations in the standard risk population. The overall mortality rate was $3.9 \%$. All had replacement of the ascending aorta and entire arch. A few centers of excellence are reporting excellent outcomes of arch repair with a history of thoracic aortic surgery. However, it is difficult for other centers to reproduce as good results as reported by these centers of excellence. In 4 of the largest recently reported series of elephant trunk procedures, ${ }^{19-22}$ the cumulative mortality for the 2 procedures and from deaths in the interval between the 2 procedures (commonly from aortic rupture) exceeded $20 \%$. In our experience, 3 of the 11 patients with a history of thoracic aortic repair were treated in an emergency setting for a ruptured aneurysm. None of the patients treated in an elective setting with prior thoracic aortic repair died after a mean follow-up of 29.9 months. In this subgroup, the estimated survival at 1 year is $100 \%$.

The chief limitation of our study is the relatively small number of patients, which affects the power of the study. Our study was not powered to detect differences in clinical outcomes.

Although the endovascular option can provide distinct advantages over conventional open surgery for repair of aortic arch aneurysm, it is clear that the arch is the most challenging area for stent-graft placement. Endovascular aortic arch reconstruction, although some of these adjunctive procedures remain major operations, provides an attractive alternative for treating aortic arch diseases in high-risk patients who would otherwise be unsuitable for open repair, with acceptable primary results and encouraging midterm efficacy to prevent rupture. This technique further expands the aortic territory that can be grafted. Until branched aortic stent grafts become available, debranching techniques combined with aortic stent grafting provide the optimal approach for the management of aortic arch lesions in high-risk patients.

\section{References}

1. Ishimaru S. Stent-grafting of the aortic arch. J Endovasc Ther. 2004;11:62-71.

2. Griepp RB. Cerebral protection during aortic arch surgery. J Thorac Cardiovasc Surg. 2001;121:425-7.

3. Sundt TM 3rd, Orszulak TA, Cook DJ, Schaff HV. Improving results of open arch replacement. Ann Thorac Surg. 2008;86:787-96.

4. Dake MD, Miller DC, Semba CP, Mitchell RS, Walker PJ, Liddell RP. Transluminal placement of endovascular stent-grafts for the treatment of descending thoracic aortic aneurysms. N Engl J Med. 1994;331:1729-34.

5. Bergeron P, Mangialardi N, Costa P, Coulon P, Douillez V, Serreo E, et al. Great vessel management for endovascular exclusion of aortic arch aneurysms and dissections. Eur J Vasc Endovasc Surg. 2006;32:38-45.

6. Czerny M, Gottardi R, Zimpfer D, Schoder M, Grabenwoger M, Lammer J, et al. Transposition of the supraaortic branches for extended endovascular arch repair. Eur J Cardiothorac Surg. 2006;29:709-13.

7. Gottardi R, Lammer J, Grimm M, Czerny M. Entire rerouting of the supraaortic branches for endovascular stent-graft placement of an aortic arch aneurysm. Eur J Cardiothorac Surg. 2006;29:258-60.

8. Cinà CS, Safar HA, Maggisano R, Bailey R, Clase CM. Subclavian carotid transposition and bypass grafting: consecutive cohort study and systematic review. $J$ Vasc Surg. 2002;35:422-9.

9. Peterson BG, Eskandari MK, Gleason TG, Morasch MD. Utility of LSA revascularization in association with endoluminal repair of acute and chronic thoracic aortic pathology. J Vasc Surg. 2006;43:433-9.

10. Buth J, Harris PL, Hobo R, van Eps R, Cuypers P, Duijm L, et al. Neurologic complications associated with endovascular repair of thoracic aortic pathology: incidence and risk factors. A study from the European Collaborators on Stent/Graft Techniques for Aortic Aneurysm Repair (EUROSTAR) registry. J Vasc Surg. 2007;46:1103-10.

11. Feezor RJ, Martin TD, Hess PJ, Klodell CT, Beaver TM, Huber TS, et al. Risk factors for perioperative stroke during thoracic endovascular aortic repairs (TEVAR). J Endovasc Ther. 2007; 14:568-73.

12. Fattori R, Lovato L, Buttazzi K, Di Bartolomeo R, Gavelli G. Extension of dissection in stent-graft treatment of type B aortic dissection: lessons learned from endovascular experience. J Endovasc Ther. 2005;12:306-11.

13. Kpodonu J, Preventza O, Ramaiah VG, Shennib H, Wheatley GH 3rd, RodriquezLopez J, et al. Retrograde type A dissection after endovascular stenting of the descending thoracic aorta. Is the risk real? Eur J Cardiothorac Surg. 2008;33:1014-8.

14. Chuter TA, Schneider DB, Reilly LM, Lobo EP, Messina LM. Modular branched stent-graft for endovascular repair of aortic arch aneurysm and dissection. $J$ Vasc Surg. 2003;38:859-63.

15. Criado FJ. A percutaneous technique for preservation of arch branch patency during thoracic endovascular aortic repair (TEVAR): retrograde catheterization and stenting. J Endovasc Ther. 2007;14:54-8.

16. Inoue K, Hosokawa H, Iwase T, Sato M, Yoshida Y, Ueno K, et al. Aortic arch reconstruction by transluminally placed endovascular branched stent-graft. Circulation. 1999;100:316-21.

17. Canaud L, Alric P, Laurent M, Baum TP, Branchereau P, Marty-Ané CH, et al. Proximal fixation of thoracic stent-grafts as a function of oversizing and increasing aortic arch angulation in human cadaveric aortas. J Endovasc Ther. 2008;15:326-34.

18. Kouchoukos NT, Masetti P, Mauney MC, Murphy MC, Castner CF. One-stage repair of extensive chronic aortic dissection using the arch-first technique and bilateral anterior thoracotomy. Ann Thorac Surg. 2008;86:1502-9.

19. Svensson LG, Kim KH, Blackstone EH, Alster JM, McCarthy PM, Greenberg RK, et al. Elephant trunk procedure: newer indications and uses. Ann Thorac Surg. 2004;78:109-16.

20. LeMaire SA, Carter SA, Coselli JS. The elephant trunk technique for staged repair of complex aneurysms of the entire thoracic aorta. Ann Thorac Surg. 2006;81:1561-9.

21. Schepens MA, Dossche KM, Morshuis WJ, van den Barse-laar PJ, Heijmen RH, Vermeulen FE. The elephant trunk technique: operative results in 100 consecutive patients. Eur J Cardiothorac Surg. 2002;21:276-81.

22. Estrera AL, Miller CC 3rd, Porat EE, Huynh TT, Winnerkvist A, Safi HJ. Staged repair of extensive aortic aneurysms. Ann Thorac Surg. 2002;74:1803-5. 